\title{
Skin conductance, heart rate, and attention to the environment in two stressful situations ${ }^{1}$
}

\begin{abstract}
ROSS W. BUCK, Laboratory of Clinical Science, University of Pittsburgh Medical School, Pittsburgh, Pa. 15213, ROSS D. PARKE, University of Wisconsin, Madison, Wis. 53706, and MARIANNE BUCK, Pittsburgh, $\mathrm{Pa}$.
\end{abstract}

Physiological and behavioral responses to two stressful situations were studied in the context of an experiment on affiliation. Male $S$ s were threatened with either the prospect of electric shock or the prospect of sucking on infantile oral objects. The threat of shock was associated with an increase in both skin conductance and heart rate and in a decrease in looking around the room. The threat of sucking on infantile objects was associated with an increase in skin conductance, heart-rate deceleration, and an increase in the duration of looking around the room.

This paper is concerned with two kinds of stressful situations that have appeared in the literature on stress and affiliative behavior. One situation involves the threat of strong shocks, which is generally regarded as producing "fear," and which has been found to lead to an increase in affiliative behavior among some Ss (Schachter, 1959). The other situation was designed by Sarnoff \& Zimbardo (1961), and involves the threat of sucking on infantile oral objects. These authors label the state produced by this manipulation "anxiety," following Freud's (1936) distinction between fear as a response to an objectively harmful stimulus and anxiety as a response to an objectively harmless object that is associated with some repressed motive. They assume that the prospect of sucking on such objects associated with infantile oral behavior as baby bottles, nipples, and pacifiers arouses repressed motives associated with oral libido.

The present experiment was directly concerned with affiliative responses to these different situations. These results have been reported in detail elsewhere (Buck \& Parke, 1969). The present paper describes unexpected differences between the physiological and behavioral responses to these two stressful situations that occurred before the manipulation relevant to affiliation.

SUBJECTS AND PROCEDURE

The Ss were 120 male undergraduates from the $S$ pool of the introductory psychology course at the University of
Wisconsin. A total of 14 pilot Ss were run first to insure that the two stress manipulations were comparable in stressfulness.

The Ss were seated in a room directly in front of, and facing away from, a one-way mirror. The mirror was concealed by a cloth that was sheer enough for S's head movements to be observed through the mirror from the next room.

Electrodes for measuring heart rate (HR) and skin conductance (SC) were attached to S's arms, and he was left alone for $7 \mathrm{~min}$. During the last $2 \mathrm{~min}$, the $\mathrm{E}$ monitored the frequency and duration of $S$ 's head movements through the one-way mirror. A head movement was scored if $S$ turned his head enough for either ear to disappear from the silhouette of the head.

At the end of this baseline period, one of two stress manipulations was delivered. Half the Ss were told that they would receive a series of strong electric shocks. The other Ss were told that they would have to suck on a number of infantile oral objects, which included a baby bottle, a breast shield, a pacifier, and two nipples from nursing bottles. For convenience, the former manipulation will be labeled the fear condition and the latter, the embarrassment condition. In the fear condition, E said, "The stimuli we are using in this experiment are electric shocks ... I want to be completely honest with you and tell you that these shocks will hurt ... In order to learn anything at all using these physiological measures, the shocks must be intense ... Of course, the shocks are safe and can't possibly do any damage." $E$ then attached a bogus shock apparatus to S's right wrist.

In the embarrassment condition, $\mathrm{E}$ placed a box with the infantile oral objects on the table to the left of $S$ and opened it. As he did so, E said, "Here are a number of objects, namely, a baby bottle, a breast shield, a pacifier, and a couple of nipples. In a few minutes I'd like you to take each of these objects into your mouth and suck on it for a few seconds... This will allow us to gauge your physiological sensitivity to such oral stimulation."

All Ss were told that the actual stimulation would not take place for several minutes. $E$ placed the earphones on $S$ 's head and promised that no stimulation would take place until he called $S$ over the earphones. $E$ then went into the next room and monitored S's head movements for 105 sec. The changes in S's physiological responses and head movements from the initial rest period to the postinstructional stress period constitute the results for the present paper. No shock or sucking ever actually took place.

An attempt was made to place the shock electrode and box of oral objects on an angle of approximately 20-25 deg from S's line of sight. In this position, $S$ would not have to turn his head to look at either of these objects. Therefore, in most cases, the scoring of head turns indicated that $S$ was looking around the room.

\section{QUANTIFICATION OF DATA}

Skin conductance and HR were monitored continuously by a Beckman polygraph equipped with a Type 9292A skin-resistance coupler and a Type 9857 cardiotachometer coupler. Zinc sulfate electrode paste and $1 / 4$-in. zinc electrodes were used to measure SC (Lykken, 1969). The electrodes were placed in a unipolar arrangement, as suggested by Montagu \& Coles (1966) for conductance measurement. The active electrode was placed on the second finger of the left hand and the indifferent electrode on the left forearm. The electrodes for HR measurement were located on both forearms just below the elbows.

Physiological data were scored for $2 \mathrm{~min}$ before and $2 \mathrm{~min}$ after the stress manipulation. Mean SC level scores were obtained by averaging the log of the reciprocals of five resistance readings spaced $30 \mathrm{sec}$ apart during each period. Skin-conductance response scores were obtained by counting the total number of deflections in SC larger than 4 micromhos during the two periods. Mean HR scores were computed by counting the total number of beats that occurred within a 60-sec interval beginning $30 \mathrm{sec}$ after each $2-\mathrm{min}$ period started and ending $30 \mathrm{sec}$ before the period ended. Peak HR was scored by the method of mean cyclic maxima described by Malmstrom, Opton, \& Lazarus (1965). The readings at the peak of each cyclic increase in HR were summed and averaged in beats per minute for each 2-min baseline period. A HR peak was defined as "any cardiotachometer reading of a heart rate faster than the readings immediately preceding and succeeding it [Malmstrom, Opton, \& Lazarus, 1965, p. 548]." This measure could be computed for only $48 \mathrm{Ss}$ in each of the two stress conditions because of malfunctions in the cardiotachometer.

Behavioral data were scored for $2 \mathrm{~min}$ before and $105 \mathrm{sec}$ after the stress manipulation. The latter period began $15 \mathrm{sec}$ after $\mathrm{E}$ entered the control room following the stress manipulation. The frequency measure of S's head movements was obtained by counting the total number 
Table 1

Physiological and Behavioral Responses to the Stressful Situations

\begin{tabular}{|c|c|c|c|c|c|c|}
\hline \multirow[b]{3}{*}{ Measure } & \multicolumn{6}{|c|}{ Types of Stress } \\
\hline & \multicolumn{3}{|c|}{ Fear } & \multicolumn{3}{|c|}{ Embarrassment } \\
\hline & $\begin{array}{c}\text { Mean Pre- } \\
\text { Stress Level }\end{array}$ & $\begin{array}{c}\text { Mean } \\
\text { Change }\end{array}$ & $\mathbf{t}$ & $\begin{array}{c}\text { Mean Pre- } \\
\text { Stress Level }\end{array}$ & $\begin{array}{c}\text { Mean } \\
\text { Change }\end{array}$ & $\mathrm{t}$ \\
\hline $\begin{array}{l}\text { Skin Conductance } \\
\text { Level (Log } \mu \text { mhos } \\
\text { X 100) }\end{array}$ & 94.76 & +6.95 & $4.68 * *$ & 96.59 & +3.67 & $5.13^{* *}$ \\
\hline $\begin{array}{l}\text { Number of Skin } \\
\text { Conductance } \\
\text { Responses }\end{array}$ & 4.35 & +7.12 & $9.25 * *$ & 5.03 & +2.72 & $4.45 * *$ \\
\hline $\begin{array}{l}\text { Mean Heart Rate } \\
\text { (Beats/Min) }\end{array}$ & 75.48 & +1.38 & 1.57 & 74.88 & -2.87 & $3.79 * *$ \\
\hline $\begin{array}{l}\text { Peak Heart Rate } \\
\text { (Beats/Min) }\end{array}$ & 82.34 & +2.91 & $3.02 * *$ & 81.19 & -0.63 & 0.63 \\
\hline $\begin{array}{l}\text { Mean Frequency } \\
\text { of Looking }\end{array}$ & 1.75 & -0.65 & $2.49 *$ & 1.70 & +0.02 & 0.83 \\
\hline $\begin{array}{l}\text { Mean Duration of } \\
\text { Looking (Sec) }\end{array}$ & 28.47 & -21.06 & $5.13^{* *}$ & 22.50 & +17.27 & $3.39 * *$ \\
\hline
\end{tabular}

of movements within the two periods. The duration measure consisted of the total amount of time spent with the head tumed to the left or right during these periods. The latter was recorded by $\mathbf{E}$ on a standard electric timer operated by a microswitch. RESULTS AND DISCUSSION

Five postexperimental questionnaire items were designed to reveal whether or not the manipulations of fear and embarrassment were differentially stressful. The $S$ rated how upset he felt, and how upset he thought most students would feel, at the stress manipulation. In addition, each $S$ rated his mood before and after the experiment along the dimensions of calm-tense, pleasant-unpleasant, and embarrassed-not embarrassed, and change scores were computed. There were no significant differences between fear and embarrassment Ss on any of these measures, suggesting that the two manipulations did not differ greatly in stressfulness.

The results for the physiological and behavioral measures are summarized in Table 1. Both of the stress manipulations were accompanied by significant increases in SC level and SC response scores. Analyses of variance revealed that the fear condition was associated with a significantly greater increase than was the embarrassment condition on both measures $(F=4.61, p<.05$ for SC level; $F=19.88$, $\mathrm{p}<.001$ for $\mathrm{SC}$ response).

The fear manipulation was associated with a nonsignificant increase in mean HR. The embarrassment condition, however, led to significant $H R$ deceleration on the mean HR measure. An analysis of variance revealed that the difference in the mean HR response to the two conditions was significant $(F=13.50, p<.001)$.

The fear manipulation led to a significant increase on the peak HR measure. The embarrassment condition was associated with a nonsignificant decrease on this measure. An analysis of variance revealed that the peak HR response to the two conditions was significantly different $(\mathrm{F}=6.23, \mathrm{p}<.05)$.

The fear condition led to a significant decrease in looking around the room in terms of both the frequency and the duration of looking responses. The embarrassment manipulation led to a nonsignificant tendency for an increase in attending to the room on the frequency measure and to a significant increase on the duration measure. Analyses of variance revealed that the change in attending behavior induced by the manipulations was significantly different for the duration measure $(F=37.33, p<.001)$ and nearly significant for the frequency measure $(\mathrm{F}=3.91, \mathrm{p}<.06)$.

The embarrassment manipulation was associated with an increase on SC measures, HR deceleration, and an increase in looking around the room. The fear manipulation led to a larger increase on SC measures, an increase on the peak HR measure, and a decrease in looking around the room.

These results were unanticipated and any attempt to interpret them must be

regarded as provisional. However, it might be noted that the patterns of response to the fear and embarrassment conditions may have parallels with the response patterns that Lacey and his colleagues have associated with environmental rejection and acceptance. Lacey (1959) and Lacey, Kagan, Lacey, \& Moss (1963) reported finding HR deceleration and SC increase to tasks that seemed to demand that the $S$ pay attention to environmental stimuli. On the other hand, both SC and HR increased during tasks that seemed to demand a rejection of environmental events. The present results also suggest an association between directional fractionation and attention to the environment, if the differential changes in looking behavior are assumed to be analagous to envitonmental acceptance and rejection. Further research is needed to determine if this analogy is valid.

\section{REFERENCES}

BUCK, R., \& PARKE, R. Behavioral and physiological response to the presence of another person in two stressful situations. Paper presented at the meeting of the Eastern Psychological Association, Philadelphia, 1969.

FREUD, S. The problem of anxiety. New York: Norton, 1936.

LACEY, J. I. Psychophysiological approaches to the evaluation of psychotherapeutic process and outcome. In E. Rubenstein and M. Parloff (Eds.), Research in psychotherapy. Vol. 1. Washington, D. C.: American Psychological Association, 1959. Pp. 161-196.

LACEY, J. I., KAGAN, J., LACEY, B. C., \& MOSS, H. A. The visceral level: Situational determinants and behavioral correlates of autonomic response. In $\mathrm{P}$. Knapp (Ed.), Expressions of the emotions in man New York: International University Press, 1963. Pp. $160-208$.

LYKKEN, D. T. Properties of electrodes used in. electrodermal measurement. Journal of Comparative \& Physiological Psychology, $1959,52,629-634$.

MALMSTROM, E., OPTON, E., \& LAZARUS, R. Heart rate measurement and the correlation of indices of arousal. Psychosomatic Medicine, $1965,27,546.556$.

MONTAGU, J. D., \& COLES, E. M. Mechanism and measurements of the gatvanic skin response. Psychological Bulletin, 1966, 65, 261-279.

SARNOFF, I., \& ZIMBARDO, P. G. Anxiety, fear, and social affiliation. Joumal of Abnormal \& Social Psychology, 1961, 62, 356-363.

SCHACHTER, S. The psychology of affiliation. Stanford: Stanford University Press, 1959. NOTE

1. This research was supported by NIH Training Grant 5-T1-MH-07304-07 and by Graduate School Research Funds from the University of Wisconsin. 